\title{
CONSUMER BEHAVIOUR OF SLOVAK HOUSEHOLDS IN THE SPHERE OF ORGANIC FOOD IN THE CONTEXT OF SUSTAINABLE CONSUMPTION
}

\section{Kita, P., Žambochová, M., Strelinger, J., Kitová Mazalánová, V.}

Pavol Kita / University of Economics in Bratislava, Faculty of Trade, Department of Marketing, Dolnozemská cesta 1, 85235 Bratislava, Slovakia.E-mail: pavol.kita@euba.sk

Marta Žambochová / J. E. Purkyne University in Usti nad Labem, Faculty of Social and Economic Studies, Department of Mathematics and Management, Pasteurova 1, 40096 Ústí nad Labem, Czech Republic.E-mail: Marta.Zambochova@ujep.cz

Ján Strelinger / University of Economics in Bratislava, Faculty of Applied Languages, Department of English Language, Dolnozemská cesta 1, 85235 Bratislava, Slovakia. E-mail: jan.strelinger@euba.sk

Veronika Kitová Mazalánová / Comenius University in Bratislava, Faculty of Arts, Department of Pedagogy and Andragogy, Gondova 2, 81102 Bratislava, Slovakia. E-mail: veronika.mazalanova@uniba.sk

\section{Abstract}

Consumption styles in most modern societies are characterised by internal diversity. This situation reflects the paradox of the postmodern world in which two different trends consumerism and greening consumption, compete for the hearts, minds and portfolios of buyers. The popularity of one of the above trends depends on society's standards and the level of awareness of its citizens. The article aims to present Slovak consumers' behaviour in terms of sustainable consumption in the field of organic products. Concerning the multifaceted nature of organic food consumption, empirical research has taken into account various aspects of the potential of individual respondents and the general characteristics of their households. The survey conducted from January to May 2019 involved 1,373 individuals who live in Slovakia. The respondents' selection criteria did not consider whether or not they had food allergies or intolerances, whether they were vegetarian or vegan, or whether they liked most foods. The paper used the clustering of objects method, especially the Two-Step method. The research questionnaire concerns consumers who have a positive attitude about organic foods considering the importance of their health.

Implications for the Central European audience: The development of organic food markets is stimulated by accepting the Agenda 2030 for sustainable development. The purpose of this article is to propose elements of reflection for economic entities facing the challenges of sustainable consumption. The increased interest of Slovak consumers in organic food is linked with their interest in living a healthier life. The theoretical framework of the article focuses on the significance of consumer behaviour and the consumption of bioproducts. The practical support of consumption in-home organic food is one of the main tasks of the Programme for the Development of the Country until the year 2020 and the Action Plan of the Development of Agriculture for the years 2014-2020. 
Keywords: organic food; sustainable consumption; consumer behaviour

JEL Classification: E21, E71, I15, M00

\section{Introduction}

The recent increase in consumption is directly or indirectly reflected in the environment. The concept of sustainable consumption is a stimulus for important changes in consumer behaviour. Environmental protection is becoming more and more important, which is reflected in the gradual increase in bio food consumption and the awareness of the impacts of everyday shopping and consumption. Every company deems it important to be aware of consumer attitudes about the consumption of products; therefore, it is necessary to identify consumer behaviour within the context of responsible consumers' attributes. Sustainable consumption represents a change in the way of life of the consumer; it focuses on reaching a level that fulfils basic needs and considers the prerequisites of sustainable development. It describes the use of products and services that minimise the use of natural resources, decreases the amount of waste and respects the interests of future generations. Individuals who choose such a model are aware that life satisfaction is also influenced by factors such as access to education, health, security, employment, social justice, and the environment's state.

\section{Theoretical framework}

Knowledge of consumer behaviour is necessary for deciding about market orientation and marketing, and marketing communication on the consumer products and services markets. A company chooses its customers' target groups and the products offered to them based on its understanding of consumer behaviour. However, consumers' current and potential needs are not the only measures of market orientation; the greening of consumption trend influences the demand and competitiveness of enterprises and weakens the influence of consumerism. The trend that is linked to the greening of consumption, the decreasing of consumption and responsible consumption is becoming more important and influences participants' behaviour on the market. The greening of consumption can be understood as an increased interest in environmental questions, value and respect for the environment. In recent years, the influence of consumers on trade decisions is considered to be significant. It is increasing due to the fast development of communication technologies and the spread of information that influences other participants' behaviour on the market. As a result, consumers can motivate manufacturing and commercial enterprises on the products they offer, which are in accordance with the principles of sustainable development, support rational consumption, restrict waste of raw materials and thus the overuse of natural wealth (Kita et al., 2020). The consumer can be considered one of the main protagonists in responsible consumption. According to economic literature, a responsible consumer is characterised by different attributes (Lecompte \& Valette-Florence, 2006; Makaoui \& Taphanel, 2018; Webster, 1975; Wróbel, 2017). As far as foodstuffs are concerned, a responsible consumer will probably be a consumer who, as a citizen, is directly affected by the regulatory and initiative approaches of local authorities towards the environment (separation of waste, recycling, energy and water conservation, etc.). The consumer remains in direct contact with all events and phenomena 
in the climate and economic changes that inform global information and communication networks. As a buyer of products and services on the market, a consumer is one of the stakeholders whose needs must be identified and satisfied by enterprises (Binninger \& Robert, 2008). As a result of their rational decisions, consumers improve the quality of life and consumption of food from bio-agriculture and organic food and contribute to creating new workplaces in this sphere. Organic food represents a special group of food that has higher qualitative parameters. During its processing, energy efficiency must be maintained, exhaustible resources must be conserved, waste must be minimised, the environment must be protected, and secondary contamination must be prevented. The labelling and promotion of products for sale as 'bio-products' are possible when $95 \%$ of the ingredients of agricultural origin are made according to the rules of ecological agriculture. The consumption of organic food in Europe is one of the decisive elements in the strategy focused on sustainable development. The existence and viability of the organic food market depend on the connection that consumers consider important regarding a healthy lifestyle and healthy food (Kita et al., 2020) and care for the environment. The development of organic food markets is stimulated by Agenda 2030 for Sustainable Development. The consumption of organic food contributes to sustainable consumption, which acknowledges that natural resources are limited and corresponds to the consumer's commitment (Chabault, 2017) regarding the quality of their personal and collective life.

\section{Methodology}

This empirical research on the multifaceted nature of the consumption of organic food took into consideration various aspects of the potential of respondents and the general characteristics of their households. The research aimed to obtain knowledge of the attitudes of consumers in the context of responsible consumer attributes. The research was based on the following hypothesis: the attitudes of Slovak consumers' households towards food consumption influence their orientation and shopping behaviour towards sustainable consumption. Based on theoretical knowledge, 21 consumer attributes relevant to responsible consumption were formulated. The respondents were asked to express their opinion on the researched phenomenon by marking a certain position on the 7-point Likert scale. The questionnaire also contained questions related to respondents' general characteristics and their households with respect to motivation, perception and attitudes, preferences generally influenced by education, employment, age, the financial situation in the household, residence, region, and if a man or woman made decisions. Empirical research was conducted in the form of personal interviews with each respondent. Pre-research on a sample of 200 respondents was carried out before the anonymous empirical research was conducted. During the pre-research phase, the comments of respondents dealing with the questionnaire structure were taken into account in the final adjustment. The research used an intentional selection of 1,373 units of basic collection based on volunteering and availability to obtain the widest and most accurate information. 741 women (53.9\%) and 632 men $(46.3 \%)$ took part in the research, and were divided into the following generations (Williams et al., 2010):

a) generation $Z$, or the internet generation, born after 2000 , in 2019 , the age span was 0 to 19 years of age (Miller \& Washington, 2011). The lowest age group has 
represented the age of 17 with respect to the fact that the Slovak statistical institute considers a young person someone from 17 to 29 years of age;

b) generation $Y$ or the millennials, born between 1981 and 1999; in 2019, the age span was 20 to 38 years of age (Bolton et al., 2013; Foscht et al., 2009);

c) generation X, born between 1966 and 1980; in 2019, the age span was 39 to 53 years of age (Brosdahl \& Carpenter, 2011);

d) baby-boom generation born between 1946 and 1965; in 2019, the age span was 54 to 73 years of age (Maciejewski, 2018);

e) the silent generation, born in the years 1930 - 1945; in 2019, the age span was 74 years of age and above (Maciejewski, 2018).

The largest group in the sample was represented by generation $X(31.9 \%)$. Technological and economic progress accompanying social changes have changed the present person into a working, shopping, relaxing and paying a person in virtual reality. From this point of view, consumers from generation $Y(20.9 \%)$ born between 1981 and 1999, and consumers from the youngest generation $Z(25.4 \%)$ born after 2000, represent significant target groups for many producers and sellers of foodstuffs. According to Maciejewski (2018), a consensus that would precisely limit these two generation groups does not exist in the theoretical sphere. As a result, the generational boundaries tend to overlap. Both groups in the sample represented $46.3 \%$ of the sample. Generation Z, which comprises the second largest group of respondents in the sample, is perfectly oriented in the world of technical news (Knežević \& Delić, 2017). Its members are also called 'welfare kids' equipped with smartphones and tablets. They require new shops that offer goods and services at the right time and place at a reasonable price. The silent generation represented $12.3 \%$ of the respondents. The smallest group was comprised of the baby boomer generation (9.2\%). The distribution of respondents according to generational categories and gender is shown in Table 1.

Table 1 | Generation categories of respondents

\begin{tabular}{lccccc}
\hline & Generation Z & Generation Y & $\begin{array}{c}\text { Generation } \\
\mathbf{X}\end{array}$ & $\begin{array}{c}\text { Generation } \\
\text { baby boomer }\end{array}$ & $\begin{array}{c}\text { Silent } \\
\text { Generation }\end{array}$ \\
\hline Men & 154 & 138 & 196 & 63 & 81 \\
Women & 196 & 149 & 243 & 64 & 89 \\
Total & 350 & 287 & 439 & 127 & 170 \\
\hline
\end{tabular}

Source: authors' calculation

The largest group of respondents were from cities (Table 2) with over 5000 inhabitants. $25.3 \%$ were from cities with over 201000 inhabitants, and $21.4 \%$ were from towns with less than 5000 inhabitants.

The research results by Robson et al. (2016) confirm that consumers prefer convenience foods or foods prepared away from home. They are more calorically dense and of inferior nutritional quality, as they tend to be higher in saturated fats, sodium, and cholesterol, and lower in calcium and dietary fibres, compared to foods prepared at home, and the portions are often larger than the recommended portion. The investigation of consumer preferences 
is considered to be one of the key concepts in the analysis of consumer behaviour (Vojáček, 2011).

Table 2 | Generation categories of respondents

\begin{tabular}{|c|c|}
\hline Size of settlements & Share in \% \\
\hline towns with up to 5,000 inhabitants & 21.4 \\
\hline Cities with up to 50,000 inhabitants & 34.3 \\
\hline Cities with 51,000 to 100,000 inhabitants & 18.4 \\
\hline $\begin{array}{l}\text { Cities with } 101,000 \text { to } 200,000 \\
\text { inhabitants }\end{array}$ & 0.3 \\
\hline Cities with 201,000 inhabitants & 25.3 \\
\hline
\end{tabular}

Source: authors' calculation

The use of cluster analysis and decision trees as segmentation tools is mentioned in the literature (Brida et al., 2014; Grossmanová et al., 2016).

We performed consumer segmentation using cluster analysis, especially the two-step method implemented in the SPSS statistical system. The input variables in the analysis were the respondents' opinion characteristics; the output variable was the identification of the cluster to which they belonged. The resulting clustering is of fair quality. Subsequently, we created several classification trees to get an overview of the segment structure created in the cluster analysis. We created two groups of trees. In both cases, the explanatory variable was cluster membership. In one group, the explanatory variables were opinion characteristics; in the other group, the explanatory variables were socio-demographic characteristics. In both groups, we created trees using several algorithms that are implemented in the SPSS statistical system.

\subsection{Research questionnaire}

Based on the above findings, we formulated a research questionnaire on organic food consumption. We assumed that the respondents had a positive attitude toward organic foods concerning their health. According to Kita (2017, p. 100), as a slope and the individual's predisposition to respond to the subject favourably or unfavourably. Patch et al. (2005) 's attitude considered the intention to consume these foods as the only significant predictor. For example, Nystrand and Olsen (2020) stress nutrition and health knowledge and information; cognitive and sufficient antecedents such as attitudes, perceptions, and beliefs; product properties; and socio-demographic variables as important for consumer choices regarding organic foods.

\subsection{Data analysis}

Cluster analysis deals with the similarity of data items (Řezanková, 2009). It resolves the division of a set of items into several unspecified groups (clusters) so that items from different clusters are the least similar to each other. 
Cluster analysis can be carried out with different methods, which differ according to the way of determining the similarity of items (a measure of similarity) and with clustering methods (hierarchical and non-hierarchical) (Grossmanová et al., 2016).

The cluster analysis method's selection depends on whether the source data or aggregated data (e.g. table of frequency or matrix of similarities) are available. If the source data are available, the methods are dependent on the type of variables (nominal, ordinal and quantitative variables).

Statistical systems usually include both a hierarchical algorithm for which the result is depicted in the form of a so-called dendrogram and a non-hierarchical iterative algorithm $k$ means and a two-dimensional cluster analysis. A two-step method was implemented in version 11.5 of the statistical SPSS system. The two-step method was the most suitable dataprocessing method, mainly due to its ability to objectively determine the optimal number of clusters without requiring a user.

The aim of constructing decision trees (Žambochová, 2008) was to create the most homogeneous sets possible concerning the explained variable. The tree's root represents the entire set of data, which is recursively divided by using specific decision criteria related to the explanatory variables. The resulting tree sheets include sets of items that could have the same value as the explained variable. Two types of decision trees are used classification trees and regression trees.

In our case, the CRT (CART), CHAID and QUEST algorithms were implemented in the SPSS statistical system. Decision trees were created using these algorithms, and the one with the best quality was chosen.

\section{Results}

During the processing of research results, we dealt with consumer behaviour in terms of responsible consumption. We formulated 21 statements that reflect the attitudes of a responsible consumer (Figure 1):

- $\quad$ who uses products and services in ways that are least harmful to the environment (the type of package, blogs and cooking recipes, discarding of food, separation and recycling of waste, water and electricity conservation, shopping in trustworthy shops), and

- who increases the quality of life through rational decisions (diet advice and recommendations, analysis of proper needs, the origin of food, shopping lists, new offers, expiration dates, packaging data, price, taste, content, knowledge of the data on the package, healthy eating habits at home, food provision of households, internet shopping). 
Figure 1| 21 statements of a responsible consumer

$0 \quad 200 \quad 400 \quad 600 \quad 800 \quad 100012001400$

Our family is fully provided with food (2)

When buying food we pay attention to expiration dates (8)

11. We shop in stores which we trust

9. When buying food we pay attention to its taste and smell

10. When buying food we pay attention to price

3. Money for buying food is the most important

1. Our family eats healthy

18. We pay attention to the recycling of waste

15. When buying food we pay attention to its origin

17. Before buying food we analyze our own needs

7. When buying food we pay attention to its composition

6. We make a list before shopping

21. We know which data must be on food packaging

4. Sometimes we discard food

19. When preparing food we pay attention to water consumption

13. When preparing food we are inspired by various blogs and recipes

16. We are informed about new offers of food

20. When preparing food we pay attention to electricity consumption

14. When buying food we pay attention to the packaging

5. When preparing food we follow dietary advice

12. We buy food via internet

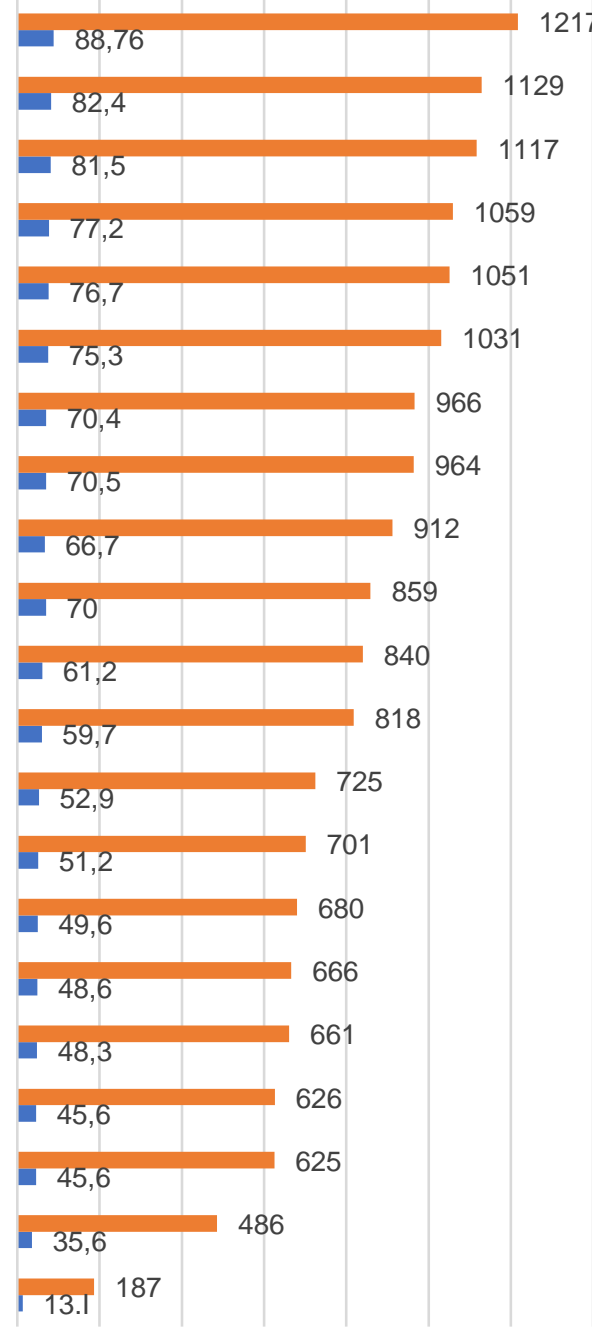

$\nabla=\%$

Source: authors' calculation

The correlation between statements could undermine the results of the methods designed to evaluate our main goal. Therefore, in the first step of the analysis, we focused on examining the relationships between the statements using a nonparametric Spearman coefficient. We created a correlation matrix. We found that almost all of the correlation coefficients are significant at the $5 \%$ level of significance, many even at the $1 \%$ level of significance. 
The highest correlation coefficients and thus, the strongest relationships were shown between the following pairs of statements:

- 'When preparing food, we pay attention to water consumption... when preparing food, we pay attention to electricity consumption'.

- 'When buying food, we pay attention to expiration dates... when buying food, we pay attention to its taste and smell'.

- 'When buying food, we pay attention to its composition... when buying food, we pay attention to its origin'.

- 'When buying food, we follow dietary advice... when buying food, we pay attention to its composition'.

- ' 'Our family is fully provided with food... money for buying food is the most important'.

Factor analysis was used to uncover latent variables and further reduce the dimension of the segmentation task. Again, all 21 monitored statements were the input variables. For this purpose, a modified questionnaire question was used in which the wording 'Sometimes we discard food' was abused. These variables are measurable because they are scales that express the degree of agreement with a given statement. Two methods are used to determine the optimal number of result factors. One is the selection of factors whose eigenvalue is greater than 1. The second option is a screen plot. The point at which the curve bends the most determines the number of factors. In our case, the second way turned out to be a better choice. Our scree plot shows that the break occurs at the number of factors equal to four. Therefore, the number of required factors was set at this value. Table 3 shows the resulting matrix component in which the assignment of the monitored variables to individual components was marked in colour. As can be seen, the fourth component only contains Item 2 , which is 'Our family is fully provided with food'.

The third component contains Items 4 (supplement to 4), 19 and 20, which means not discarding food, water-saving and electricity energy saving. All of these items are about not wasting resources.

The second component contains Items 3,10,11 and 12, i.e. money for buying food is most important, then price tracking, buying in reliable stores and buying online. All of these items are related to financial savings.

All other issues are included in the first component. These are items concerning the quality of food - the quality of raw materials, as well as instructions for proper use. 


\section{Component}

\begin{tabular}{|c|c|c|c|c|}
\hline Specification & 1 & 2 & 3 & 4 \\
\hline 1. Our family eats healthy & .501 & .005 & -.208 & .408 \\
\hline 2. Our family is fully provided with food & .318 & .451 & -.344 & .460 \\
\hline 3. Money for buying food is the most important & .278 & .361 & -.315 & .346 \\
\hline 4(sup). Sometimes we discard food & .091 & .161 & .461 & .117 \\
\hline 5. When preparing food, we follow dietary advice & .461 & -.444 & -.269 & -.003 \\
\hline 6. We make a list before shopping & .412 & .074 & .100 & -.298 \\
\hline 7. When buying food, we pay attention to its composition & .678 & -.115 & -.068 & -.062 \\
\hline 8. When buying food, we pay attention to expiration dates & .565 & .398 & .076 & -.202 \\
\hline 9. When buying food, we pay attention to its taste and smell & .559 & .312 & -.051 & -.331 \\
\hline 10. When buying food, we pay attention to price & .261 & .367 & .340 & -.335 \\
\hline 11. We buy food in the stores which we trust & .446 & .487 & .028 & -.150 \\
\hline 12. We buy food via internet & .129 & -.637 & -.132 & -.158 \\
\hline $\begin{array}{l}\text { 13. When preparing food, we are inspired by various blogs and } \\
\text { recipes }\end{array}$ & .439 & -.289 & -.363 & -.149 \\
\hline 14. When preparing food, we pay attention to the packaging & .476 & -.330 & -.269 & -.238 \\
\hline 15. When preparing food, we pay attention to its origin & .661 & .013 & -.066 & -.034 \\
\hline 16. We are informed about new offers of food & .585 & -.180 & -.061 & -.077 \\
\hline 17. Before buying food we analyse our own needs & .537 & .192 & .085 & -.112 \\
\hline 18. We pay attention to the recycling of waste & .554 & .027 & -.022 & .234 \\
\hline 19. When preparing food, we pay attention to water consumption & .534 & -.300 & .584 & .259 \\
\hline $\begin{array}{l}\text { 20. When preparing food, we pay attention to electricity } \\
\text { consumption }\end{array}$ & .463 & -.337 & .640 & .236 \\
\hline 21. We know which data must be on food packaging & .539 & -.112 & .026 & .208 \\
\hline
\end{tabular}

Source: authors' calculation

Note: Extraction Method: Principal Component Analysis. a. four components extracted.

Cluster analysis enabled consumer segmentation. The two-step method was used for this purpose. We used clustering as input variables for four statements generated by statement analysis. In the second cluster, all 21 statements were selected as transformants entering the cluster analysis dealing with sustainable consumption. The clustering quality was comparable in both cases, which was probably because the correlation between the original statements was generally significant, but not very strong. Besides, since the resulting clusters formed based on all the original statements were more interpretable, we used this for evaluation. The resulting aggregation quality was relatively poor, but marginally applicable 
(the Silhouette coefficient reached 0.2). Five comparatively large clusters were formed (the smallest contained $17.4 \%$ and the largest $23.9 \%$ of all items), which is a positive result. Subsequent analysis using classification trees characterised the formation of clusters both in terms of views and socio-demographic characteristics. The results are summarised in Table 4.

\section{Table 4 | Summary of results of cluster analysis}

\section{Socio-demographic characteristics}

\section{Opinion characteristics}

1. cluster

- women aged 55 to 64 who don't live in towns with up to 5000 inhabitants

- they do not completely disregard electricity conservation when preparing food

- women aged 35 to 54 who live in towns with up to 50000 inhabitants

- they don't have a clear view of the expiration dates

- they don't refuse internet shopping

- they pay great attention to the origin of food

- they pay attention to food composition

2. cluster

3. cluster

4. cluster
- women aged 35 to 54 who live in the counties of Banská Bystrica and Trenčín, who described that their material situation as not very good

- men up to 54 years of age living alone or in two-member households, who described their material situation as rather worse

- consumers older than 55 years of age not living in big cities with over 200000 inhabitants, who described their material situation in the households as rather bad

- men up to 54 years of age living in two-member households
- they pay great attention to food composition

- they pay attention to food composition

- they don't pay much attention to expiration dates

- they don't need to shop in stores they trust

- they don't pay too much attention to taste and smell

- they are not interested in saving electricity when preparing food

- they are not interested in saving water when preparing food

- they have a neutral attitude towards food composition

- they don't pay attention to the country of origin

- they are not inspired by blogs or cookery recipes

- $\quad$ they are not interested in saving electricity when preparing food larger households, who have a reserved view on the material situation in the household 
5. cluster

- persons older than 55 years of age living in large households, or alone, i.e., they live either in small villages or large cities
- they have a neutral attitude towards food composition

- they don't buy food online

- $\quad$ they pay attention to country of origin

- $\quad$ they shop according to a shopping list

- $\quad$ they are interested in saving electricity when preparing food

- $\quad$ they pay attention to food composition

- $\quad$ they don't follow dietary advice

- they don't buy online

Source: authors' research

The next survey mostly focused on organic food. We segmented the respondents according to these foods. For this purpose, we again used the classification using decision trees. The item regarding organic food consumption was chosen as a dependent variable was now chosen, and socio-demographic items were chosen as explanatory variables (Table 5).

Table 5 | Frequency of consumption of organic food and specific socio-demographic characteristics

\begin{tabular}{ll}
\hline $\begin{array}{l}\text { Frequency of } \\
\text { organic food } \\
\text { consumption }\end{array}$ & \multicolumn{1}{c}{ Socio-demographic characteristics } \\
\hline 1 & $\begin{array}{l}\text { men aged } 25 \text { to } 34 \text { (generation Y), who live in a city with } 51000 \text { to } 100000 \\
\text { inhabitants }\end{array}$ \\
Daily & $\begin{array}{l}\text { men living in smaller towns with up to } 50000 \text { inhabitants, who described the } \\
\text { material situation in their households as very good }\end{array}$ \\
2 & $\begin{array}{l}\text { consumers up to } 56 \text { years of age living in towns with } 50001 \text { to } 50000 \\
\text { inhabitants }\end{array}$ \\
$\begin{array}{l}\text { Several times a } \\
\text { week }\end{array}$ & $\begin{array}{l}\text { - younger consumers of generation Y, who described the material situation in } \\
\text { their households as bad and lived either in very large cities (over } 200000 \\
\text { inhabitants) or small towns (up to } 50 \text { 000 inhabitants) }\end{array}$ \\
3 & $\begin{array}{l}\text { older consumers (from } 55 \text { years of age and older) living in very large cities } \\
\text { (over } 200 \text { 000 inhabitants), who described the material situation in their } \\
\text { households as very good }\end{array}$ \\
$\begin{array}{l}\text { Several times a } \\
\text { month }\end{array}$ & $\begin{array}{l}\text { older women (from } 55 \text { years of age and older) living in smaller towns up to } \\
50 \text { 000 inhabitants, who described the material situation in their households } \\
\text { as very good }\end{array}$
\end{tabular}


5

Never
- older consumers (from 55 years of age and older) living in smaller towns (up to 50000 inhabitants), who described the material situation in their households as good

- consumers of generation $X$ and retired people living in very small towns (up to 5000 inhabitants), who described the material situation of their households as bad

- retired men from medium-sized villages, who didn't describe the material situation of their households as good

- older women over 55 years of age from smaller villages, who described the material situation of their households as very good

Source: authors' research

The decision tree structure shows that the respondents who consume organic food every day in no way disagree with the statement 'I'm not interested in the purchase of this food'. They also don't agree with the statement' Stores with this kind of food are too far from my home', but they complain about 'In the store, where I shop, they don't have this type of food' and they don't have a clear view of the statement 'I don't trust this type of food'.

The respondents who consume organic food several times a fundamentally week disagree with the statement 'I am not interested in buying such food'. They also disagree with the claim 'Stores with this kind of organic food are too far from my home'. They don't have strong opinions, but they don't strongly agree with the statement 'I'm not interested in buying this food' and they have a feeling that 'this type of food is too expensive'. The respondents who consume organic food only occasionally agree with the statement 'This type of food is too expensive'. They don't have a clear opinion of the claim 'I don't trust this type of food'.

Consumers who don't consume organic food at all very strongly agree with the statement 'I'm not interested in purchasing such food' they are not opponents of the statement' Stores with this type of food are too far from my home'. They are also convinced that 'The store in which I shop does not carry this type of food'.

\section{Discussion}

We continued to deal with consumer behaviour from the perspective of a responsible person enabling the use of products and services in a way that is least harmful to the environment (the type of packaging, advice, blogs and cooking recipes, discarding of food, separation and recycling of waste, water and electricity consumption, shopping in trustworthy stores. We were searching for the degree to which the respondents accepted the monitored statements. For this purpose, the authors used the Friedman test with successive Post-hoc analysis. Based on the resulting $p$-values, it was determined that the respondents mostly accept the statement: 'We buy food in the stores we trust'. Subsequently, attention was paid to the separation and recycling of waste. The third most accepted statement was: 'When preparing food, we pay attention to electricity consumption'.

On the contrary, the least accepted statement was: 'When preparing food, we follow dietary advice'. Other statements did not reveal any significant differences ( $p$-value of Friedman's test reached value 0.55 , which is significantly larger than $5 \%$ of the level of importance). For 
better understanding and clarity, the following Table 6 mentions the factors with the average values of acceptance rate.

Table 6 | List of the factors with average values of acceptance from the point of view responsible person enabling the use of products and services in a way that is least harmful to the environment

\begin{tabular}{|c|c|c}
\hline \multicolumn{1}{c|}{ Specification } & Average & $\begin{array}{c}\text { Standard } \\
\text { Deviation }\end{array}$ \\
\hline 4. Sometimes we discard food & 0.12 & 1.819 \\
\hline $\begin{array}{l}\text { 5. When preparing food we follow dietary advice and } \\
\text { recommendations }\end{array}$ & -0.37 & 1.835 \\
\hline 11. We buy food in trustworthy stores & 1.64 & 1.471 \\
\hline 13. When preparing food we are inspired by blogs and cooking recipes & $-\mathbf{0 . 1 1}$ & 1.994 \\
14. When buying food we pay attention to the type of packaging & $-\mathbf{0 . 1 3}$ & $\mathbf{1 . 7 8 4}$ \\
18. We pay attention to the separation and recycling of waste & $\mathbf{1 . 1 4}$ & $\mathbf{1 . 7 6 9}$ \\
\hline 19. When preparing food we pay attention to water consumption & $\mathbf{0 . 1 7}$ & $\mathbf{1 . 8 9}$ \\
\hline 20. When preparing food we pay attention to electricity consumption & $\mathbf{0 . 0 1}$ & $\mathbf{1 . 9 1 8}$ \\
\hline
\end{tabular}

Source: authors' calculations

The second point of view regarding responsible consumption is the requirement to improve the quality of life - rational shopping (dietary advice and recommendations, analysis of own needs, the origin of food, shopping list, new offers, date of expiration, information on the package, price, taste and flavour, food composition, knowledge of the information on the packaging). We were searching for the measure which respondents accept from the monitored statements. For this purpose, the authors used the Friedman test with following Post-hoc analysis. Based on the resulting p-values, we found out that the respondents mostly accept the statement: 'When buying food, we pay attention to the expiration date' followed by the statements 'When buying food, we pay attention to its taste and flavour' and 'When buying food, we pay attention to its price' and further to a pair of factors, 'When buying food, we pay attention to its origin' and 'Before shopping, we analyse our own needs'. On the contrary, the least accepted statement was 'When preparing food, we follow dietary advice and recommendations'. For clarity, the following Table 7 lists the factors with average values of acceptance. 
Table 7 | List of factors with average values of acceptance point of view regarding responsible consumption

\begin{tabular}{l|c|c}
\hline \multicolumn{1}{c|}{ Specification } & Average & $\begin{array}{c}\text { Standard } \\
\text { Deviation }\end{array}$ \\
\hline 5. When preparing food, we follow dietary advice and & -0.37 & 1.835 \\
\hline $\begin{array}{l}\text { 6. We bummendations } \\
\text { 7. Wheod according to a pre-prepared shopping list }\end{array}$ & 0.61 & 1.856 \\
8. When buying food, we pay attention to expiration dates & 1.71 & 1.825 \\
9. When buying food, we pay attention to its taste and flavour & 1.42 & 1.526 \\
10. When buying food, we pay attention to its price & 1.35 & 1.537 \\
15. When buying food, we pay attention to its origin & 0.89 & 1.883 \\
16. We are informed about new offers of food & 0.18 & 1.812 \\
17. Before shopping, we analyse our own needs & 1 & 1.614 \\
21. We know which data must be mentioned on the packaging & 0.32 & 1.868 \\
\hline
\end{tabular}

Source: authors' calculations

In summary, in terms of responsible consumption, the respondents were most at fault for failing to follow dietary advice, failing to pay attention to the type of packaging and sometimes discarding food. The purchasing habits and consumption habits in most modern societies are variable and characterised by internal diversity. They are changing with time and according to the main purchase criterion in choosing products of a given category. This is a complicated topic relevant to the context. Concerning the increasing challenges of sustainable development, globalisation, income, healthy lifestyle, the rising quality of education, information about products etc., consumers' attitudes and consumer models within their efforts to have a healthy lifestyle are changing. The present time is a sign of sustainable consumption which increased the demand for healthy food due to the deeper changes in a contemporary model of consumption. Consumers can contribute to protecting the environment and maintaining conditions in the sphere of health protection from growers to consumption by making the proper choices. Consumer behaviour concerning these products will depend on various factors, including the level of ecological awareness, the level of knowledge and marketing activities. Changes in consumers' lifestyle, environmental pollution, and competitiveness in environmentally friendly products are important prerequisites for taking sustainable consumption in marketing activities into account. Consumer awareness of organic food is not always at the desired level; thus, they are not sufficiently favoured by purchasing these products.

The research defined the motives for and barriers to organic food purchase. Price was identified as the most significant barrier; on the contrary, the motive to buy such products was consumer confidence in these foods (51.3\% of respondents trust organic food). However, organic food is consumed less than several times a month compared to functional foods, convenience food and intermediate products. In terms of the frequency of consumption of organic foods, they are consumed mainly by men aged of 25 to 34 (generation $Y$ ), who live in a city with $51000-100000$ inhabitants and men living in towns of up to 50000 inhabitants 
who described their material situation in their households as very good. Individuals in categories $Z$ and $Y$ show organic food consumption comparable to that of young people up to 34 years of age. These consumers significantly consume more organic food than older individuals.

On the contrary, individuals from the oldest age group consume organic food the least. The results of our research characterise the degree of acceptance of organic food by consumers as well as their attitudes toward sustainable consumption. This information is crucial for developing a company's strategy, including marketing strategy and communication campaigns. The marketing communication of organic food differs from other types of marketing communication in that it must be responsible not only because it is food, but because it is a unique type of product - which influences the health, quality of life and environment of consumers. Knowledge of consumers' attitudes towards sustainable consumption and organic food consumption can improve marketing communication towards other groups. Online and offline communication should be uniform.

The message addressed to individual groups of customers should be clear, understandable, and presented in the particular focus group's language. The consumers' understanding of a message depends on how they respond to it. Marketing communication must take into account the influence and experience that has the strongest impact on existing and potential consumers at different stages of the purchasing decision, i.e. pre-purchase, purchase, consumption and post-consumption, as well as the visit preparation stage, the visit stage, and the post-visit/return home stage. Consumers should believe and trust businesses to make the best decisions for them, so it is desirable to prepare and transmit information that helps them make the right decisions and promote sustainable consumption.

\section{Conclusion}

Food consumption in Europe is one of the decisive elements in the strategies focused on sustainable development. Increasing the demand for organic products comprises one part of the deeper changes in the contemporary consumption model. The ecologisation of consumption is increasingly stimulated by a decrease in the importance of consumption in the scale of human priorities, which is more likely considered as the means and not the aim of life. Consumer behaviour towards organic products depends on various factors. It is primarily determined by attitudes that are influenced by a person's degree of ecological awareness, level of knowledge, and marketing activities in the considered age-categories and geographical places of consumption. Although the organic food market in Slovakia is still at an early stage of development, the number of stores offering ecological farming products is gradually growing; however, their assortment is still developing, and organic products are missing in many existing retail units. At the same time, the consumption of these products, mainly among the younger generations, is becoming their lifestyle. The diversity of consumer behaviour among different segments of the population concludes that consumer information on organic food is not always at the required level. Consumers are not favoured over other types of food. The findings presented herein can be used by manufacturing and commercial enterprises to respond to consumer attitudes with appropriate marketing communication models. However, they also imply an increase in the availability of specific organic food in a distribution network to improve consumers' pro-ecological behaviour. 


\section{Acknowledgement}

This article is related to the APVV project APVV-16-0232 'Consumer society' and consumer regions. Stratification of post-communist society' VEGA 1/0066/18 Model of marketing communication on the health-related purchasing behaviour of consumers.

\section{References}

Binninger, A.-S., Robert, I. (2008). Consommation et développement durable. Vers une segmentation des seinsibilit's et des compotements. La revue des sciences de gestion, 229(1), 51-59. https://doi.org/10.3917/rsg.229.0051

Bolton, R. N., Parasuraman, A., Hoefnagels, A., Migchels, N., Kabadayi, S., Gruber, T., Komarova Loureiro, Y., \& Solnet, D. (2013). Understanding Generation Y and their use of social media: A review and research agenda. Journal of Service Management, 24(3), 245-267. https://doi.org/10.1108/09564231311326987

Brida, J. G, Scuderi, R., \& Seijas, M. N. (2014). Segmenting cruise passengers visiting Uruguay: A factorcluster analysis. International Journal of Tourism Research, 16(3), 209-222. https://doi.org/10.1002/jtr.1916

Brosdahl, D. J., Carpenter, J. M. (2011). Shopping orientations of US males: A generational cohort comparison. Journal of Retailing and Consumer Services, 18(6), 548-554. https://doi.org/10.1016/j.jretconser.2011.07.005

Chabault, V. (2017). Sociologie de la consommation. Paris: Dunod.

Foscht, T., Schloffer, J., lii C. M., Chia, S. L. (2009). Assessing the outcomes of Generation-Y customers' loyalty. International Journal of Bank Marketing, 27(3), 218-241. https://doi.org/10.1108/02652320910950204

Grossmanová, M., Kita, P., \& Žambochová, M. (2016). Segmentation of consumers in the context of their space behaviour: Case study of Bratislava. Prague Economic Papers, 25(2), 189-202. https://doi.org/10.18267/j.pep.554

Kita, J. (2017). Marketing. luraEdition.

Kita, P., Žambochová, M., Keresty, J., Kitová Mazalánová, V., Kita, J. (2020). Les attitudes des consommateurs slovaques en matière d'alimentation : des efforts pour un mode de vie plus sain. In Management \& Gouvernance : Entreprises - Territoires - Sociétés, 13(23), 39-50.

Knežević, B., \& Delić, M. (2017). Young consumers' perception of problems and usefulness of mobile shopping applications. Entrepreneurial Business and Economics Review, 5(1), 43-55. https://doi.org/10.15678/EBER.2017.050103

Lecompte, A., \& Valette-Florence, P. (2006). Mieux connaître le consommateur socialement responsable. Décisions Marketing, 41(1), 67-69. https://doi.org/10.7193/DM.041.67.79

Maciejewski, G. (2018). Consumer's attitudes towards modern solutions in the retail trades. Economics and Business Review, 18(3), 69-85. https://doi.org/10.18559/ebr.2018.3.6

Miller, R. K., Washington, K. (2011). Consumer behavior: millennial consumers. Loganville: Richard K. Miller \& Associates.

Makaoui, N., \& Taphanel, L. (2018). Interagir avec le consommateur responsable: Un client atypique soumis à des tensions identitaires? La Revue des Sciences de Gestion, 289-290(1-2), 31-40. https://doi.org/10.3917/rsg.289.0031 
Nystrand, B. T., \& Olsen, S. O. (2020). Consumers' attitudes and intentions toward consuming functional foods in Norway. Food Quality and Preference, 80(3), 103-827. https://doi.org/10.1016/j.foodqual.2019.103827

Patch, C. S., Tapsell, L. C., \& Williams, P. G. (2005). Overweight consumers' salient beliefs on omega3-enriched functional foods in Australia's Illawarra region. Journal of Nutrition Education and Behavior, 37(2), 83-89. https://doi.org/10.1016/S1499-4046(06)60020-1

Řezánková, H. (2009). Cluster analysis and categorical data. Statistika. 89(3), 216-232.

Robson, S., Odar Stough, C., \& Stark, L. J. (2016). The impact of a pilot cooking intervention for parentchild dyads on the consumption of foods prepared away from home. Appetite, 99(4), 177-184. https://doi.org/10.1016/j.appet.2016.01.021

Vojáček, O. (2011). Preference Dilemma in Economics. Politická ekonomie, 59(3), 345-358.

Webster, F. (1975). Determining the characteristics of the socially conscious consumer. Journal of Consumer Research, 2(3), 188-196. https://doi.org/10.1086/208631

Williams, K. C., Page, R. A., Petrosky, A. R., \& Hernandez E. H. (2010). Multi-generational marketing: Descriptions, characteristics, lifestyles, and attitudes. Journal of Applied Business and Economics, 11(2), 21-36.

Wróbel, M. (2017). Konsumpcja odpowiedzialna - wyzwanie dla zarzadzania rozwojem. Warszawa: CeDeWu.

Žambochová, M. (2008). Data mining methods with trees. E+M Ekonomie a Management, 11(1), 126131.

The research paper passed the review process. | Received: April 19, 2020; Revised: August 10, 2020; Accepted: August 10, 2020; Pre-published online: December 28, 2020; Published: March 19, 2021. 